\title{
Challenges associated with the development of scientific projects and studies in digital health and mobile technologies
}
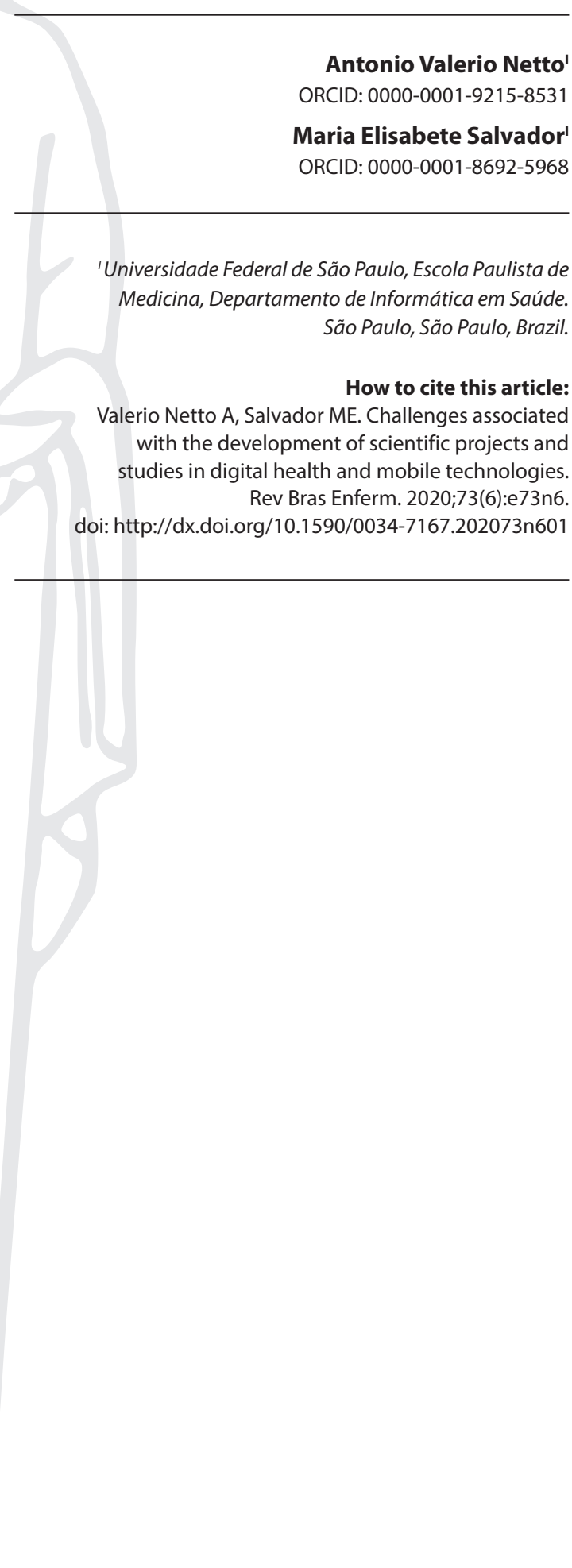

Advances in science and the promising results of health products and services have motivated professionals and researchers to study, plan, develop, implement and, above all, assess the effective and significant use of technologies. In fact, the scientific community has an expressive collection of studies and interventions on the use of technological resources in health; however, little or no scientific criteria and rigor is still observed, especially in the validation phases, including the need to obtain significant samples. In other words, to create and make full use of the potential of technologies, relevant steps need to be carried out prudently and responsibly, supported by scientific methods.

It is understood that the data from technological studies, derived from applied interventions, must be based on rigorous scientific evidence, as they are used to support clinical practice, qualification of care and decision making in patient health management. It is in this context that Evidence-Based Health (SBE) seeks to assess and reduce uncertainties in professional decision making. The Pan American Health Organization (PAHO) cites SBE as one of the major trends in medical practice in the $21^{\text {st }}$ century as well as the incorporation of technologies that allow a reliable, safe, and accurate evidence acquisition and pre-analysis ${ }^{(1)}$. It is understood that the development of a eHealth-based (Digital Health) solution must be preceded by clear evidence ${ }^{(2)}$. It is worth noting that the difficulties in incorporating digital solutions in health in Brazil are directly related to the lack of execution of the first phases of a product or service life cycle. On the other hand, application and validation are equally relevant steps.

Thus, it is worth highlighting the meaning of the aforementioned terms. Using mobile technologies in health or mHealth (mobile health) is a comprehensive part of eHealth, according to the World Health Organization $^{(3)}$. Both terms represent the use of Information and Communication Technologies (ICT) resources in health support. mHealth uses mobile and wireless technologies, such as phones, smartphones, smartwatches, patient monitoring devices, personal digital assistants, especially mobile software applications (APPs), to support health activities. eHealth translates the development and use of advanced health computing technologies, such as web technologies (clouding computing), mobile devices, sensors, bioinformatics, big data, genomics, artificial intelligence, biotelemetry, among others, including laptops, desktops, servers, television and radio, teleconferencing systems, etc. ${ }^{(4-5)}$.

Taking as an example the technological studies on APPs in health, the sequence of a product or service life cycle stands out. Generally, it begins in the basic research phase, with subsequent steps being substantially necessary, such as applied research, development, introduction, growth, maturity, and decline. In the research phase, whether basic or applied, it is difficult to set deadlines; technical risks are high and knowledge formation is not linear ${ }^{(6)}$. In this perspective, it is essential that researchers, especially academic researchers, adopt development methodologies to support the creation process. Errors in validating the solution's value proposition must be avoided. It is not enough to create only one prototype; it is necessary to 
validate a product or service (efficiency and effectiveness) with the respective target audience. Among the various methods used, one can illustrate the conduct of innovation processes by IVPM2 methodology (Iterative \& Visual Project Management Method). It is based on the application of agile management principles and practices by using project management support structures. This method is divided into vision, conception, detailed design, internal and external validation, and closure and adoption of technology $y^{(7)}$.

The vision phase determines the characteristics of the solution, the scope of the project, the stakeholders and the definition by which multidisciplinary teams (e.g. health and information technology) should work and interact. In this phase, the solution modeling is validated based on unstructured exploratory interviews, creation of flowcharts based on requirements gathering as well as the communication protocols survey.

The conception phase defines the deliverables and builds the schedule and the iteration plan (process by which repetition of one or more actions is performed) according to the "vision". Analyzes and interpretations are carried out in order to define what is necessary to build and what kind of knowledge must be acquired. System modeling is carried out, including the software and database modules, in detail, with all the procedures to be elaborated for the chosen technological platform. The standards and performance indicators to be used by the system are defined as well as data security. Finally, we identify the indicators that will be used as a parameter to verify whether the solution is adequate (clinical examinations, etc.).

The detailed design phase transfers product components in short delivery cycles, minimizing risks and uncertainties. The scrum method can be applied ${ }^{(8)}$ (set of activities and performed in a certain period) with weekly sprints. In this period, the system is developed, including the creation of communication protocols, APP interface and features, cloud computing platform, analytical algorithms, etc. The aim was to conduct the system up and running to start the validation phase.

Internal and external validation is one of the most important phases that allows to review the results delivered, analyze the current situation and team performance. In internal validation, tests are performed by Quality Analyst and a group of volunteer users of the project (functional and operational tests). Tests of system functionality (screen bugs, crash, communication, etc.) are performed, then operational tests are performed (logic and data interpretation). White box and black box and load tests can be used (volume of people accessing the system, for instance).
External validation involves choosing the group of users who will participate in pre-clinical tests, i.e., those who will really benefit from the proposed digital solution, the target audience. During this period, data collection activities (cross-sectional and longitudinal phase) are monitored to assess the system's performance. Adjustments are made to achieve the correct configuration (fault correction and performance improvement). Equally, the indicators used as parameters are assessed to check if the digital solution meets the clinical purpose.

The system is implemented in the closure and adoption phase. The professional who will operationalize the solution and end the interaction process with users must receive training (usability, adoption strategies, etc.). It is exactly at this stage that scientific studies are prepared based on preliminary results from the pre-clinical phase (detailed description of the solution and documentation of the pilot or case study, among others). Scientific publication on the creation and validation process, including all stages, gives product or service visibility and, consequently, researcher credibility.

In an economic context that requires strict control of public spending, it is relevant to control health innovations to spread. That is why health technology analysis is subject to the growing national interest in management and approval decisions ${ }^{(9)}$. Therefore, scientific methods must guide future studies and technological applications in health so that, evidently, they make sense. Technological resources must be considered from the moment that problems and needs precede the idea of creating a mobile application, not the other way around. Furthermore, it is necessary to combine ideal tools and an integrated system, so that the technological strategy clearly favors a certain population, in order to add value to the players, market access and viable economic interest. Ray et al. ${ }^{(10)}$ emphasize that "the best innovations are focused on unmet needs and not on solutions, [...] seek to prioritize investments in research and development in areas where the greatest impact can be achieved".

In this perspective, SUS (Sistema Único de Saúde -Brazilian Health System) nurses represent a category of creative professionals to use technological resources that meet the demands of practice, considering the expressive growth in the number of technology studies in the country. Innovations include concepts of novelty and change; however, it is relevant to consider the scientific evidence that permeates every moment, from the idea to validation, in the perennial search for quality of care and better performance in providing health services.

\section{REFERENCES}

1. Valerio Netto A, Petraroli AG. Modelagem de um sistema para o telemonitoramento de idosos com condição crônica baseado em biotelemetria. J Health Informat [Internet]. 2020[cited 2020 Aug 05];12(1):10-6. Available from: http://www.jhi-sbis.saude.ws/ojs-jhi/index. php/jhi-sbis/article/view/691

2. Granja C, Janssen W, Johansen MA. Factors determining the success and failure of eHealth interventions: systematic review of the literature. J Med Internet Res. 2018;20(5):e10235. doi: 10.2196/10235

3. World Health Organization-WHO. mHealth: use of mobile wireless technologies for public health. WHO-Technical Report[Internet]. 2016[cited 2020 Aug 05]. Available from: https://www.who.int/goe/publications/goe_mhealth_web.pdf 
4. Valerio Netto A, Tateyama AGP. Tecnologia de telemonitoramento e biotelemetria para apoio a implantação do cuidado híbrido para o idoso com condição crônica. J Health Inform [Internet]. 2018[cited 2020 Aug 05];10(4):103-11. Available from: http://www.jhi-sbis.saude.ws/ ojs-jhi/index.php/jhi-sbis/article/view/602

5. World Health Organization-WHO. MHealth: use of appropriate digital technologies for public health Report by the Director-General. Seventy-First World Health Assembly[Internet]. 2018[cited 2020 Aug 05]. Available from: https://apps.who.int/gb/ebwha/pdf_files/WHA71/A71_20-en.pdf?ua=1

6. Valerio Netto A. Proposta de um checklist para auxiliar na identificação de projetos de tecnologia e inovação oriundos do programa PIBITI do CNPq. Empreend, Rev Gestão Negócios [Internet]. 2020[cited 2020 Aug 05];9(1):170-87. Available from: http://fatece.edu.br/arquivos/ arquivos\%20revistas/empreendedorismo/volume9/Antonio\%20Valerio\%20Netto.pdf

7. Borba JCR, Trabasso LG, Pessoa MVP. Agile Management in Product Development. Res-Technol Manag. 2019;62(5):63-7. doi: $/ 10.1080 / 08956308.2019 .1638488$

8. Ardakani MRM, Hashemi, SM, Razzazi M. Adapting the scrum methodology for establishing the dynamic inter-organizational collaboration. J Org Chang Manag. 2018;31(4):852-66. doi: 10.1108/JOCM-07-2016-0135

9. Dubromel A, Geffroy L, Aulagner G, Dussart C. Assessment and diffusion of medical innovations in France: an overview. J Mark Access Health Policy. 2018;6(1):1458575. doi: 10.1080/20016689.2018.1458575

10. Ray PP, Amaral JF, Hinoul P. Innovation Best Practices in the Medical Device Industry. Tech Vasc Interv Radiol. 2017;20(2):90-3. doi: 10.1053/j. tvir.2017.04.004 